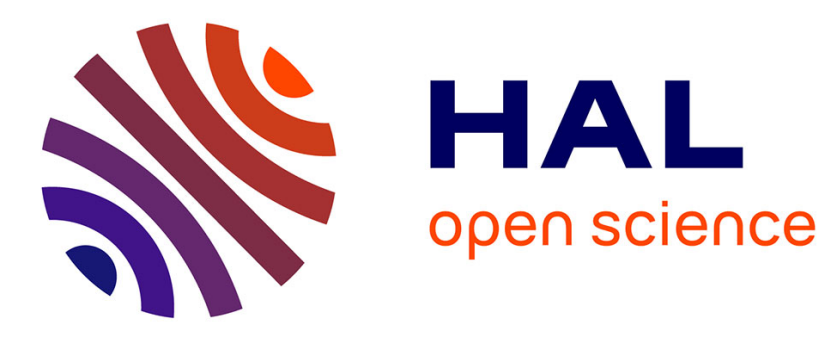

\title{
Stability of membrane in low subsonic flow
}

Ryszard Sygulski

\section{To cite this version:}

Ryszard Sygulski. Stability of membrane in low subsonic flow. International Journal of Non-Linear Mechanics, 2007, 42 (1), pp.196. 10.1016/j.ijnonlinmec.2006.11.012 . hal-00501739

\section{HAL Id: hal-00501739 \\ https://hal.science/hal-00501739}

Submitted on 12 Jul 2010

HAL is a multi-disciplinary open access archive for the deposit and dissemination of scientific research documents, whether they are published or not. The documents may come from teaching and research institutions in France or abroad, or from public or private research centers.
L'archive ouverte pluridisciplinaire HAL, est destinée au dépôt et à la diffusion de documents scientifiques de niveau recherche, publiés ou non, émanant des établissements d'enseignement et de recherche français ou étrangers, des laboratoires publics ou privés. 


\section{Author's Accepted Manuscript}

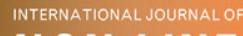

NON-LINEAR

MECHANICS

Stability of membrane in low subsonic flow

Ryszard Sygulski

PII: $\quad$ S0020-7462(07)00035-2

DOI: doi:10.1016/j.ijnonlinmec.2006.11.012

Reference: $\quad$ NLM 1320

To appear in: International Journal of NonLinear Mechanics

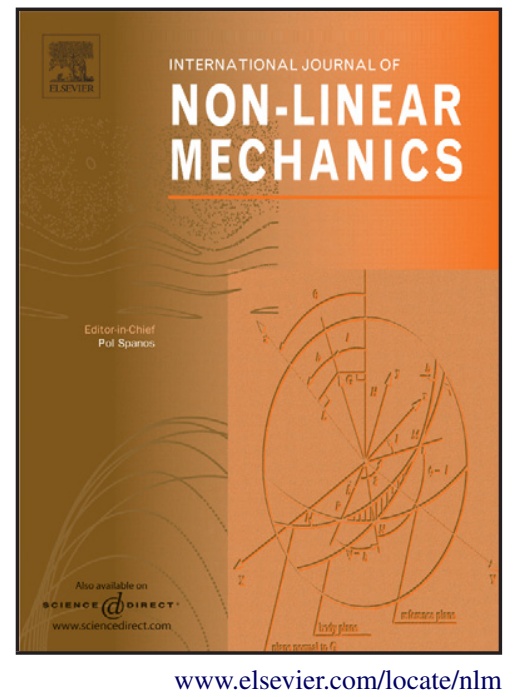

Received date: 29 June 2006

Revised date: 26 October 2006

Accepted date: 7 November 2006

Cite this article as: Ryszard Sygulski, Stability of membrane in low subsonic flow, International Journal of Non-Linear Mechanics (2007), doi:10.1016/j.ijnonlinmec.2006.11.012

This is a PDF file of an unedited manuscript that has been accepted for publication. As a service to our customers we are providing this early version of the manuscript. The manuscript will undergo copyediting, typesetting, and review of the resulting galley proof before it is published in its final citable form. Please note that during the production process errors may be discovered which could affect the content, and all legal disclaimers that apply to the journal pertain. 


\title{
Stability of membrane in low subsonic flow
}

\author{
Ryszard Sygulski \\ Institute of Structural Engineering, Poznan University of Technology \\ Piotrowo 5, 60-965 Poznan, Poland \\ e-mail: ryszard.sygulski@ikb.poznan.pl
}

\begin{abstract}
Stability of an isolated membrane lying in a uniform two-dimensional low subsonic flow is studied theoretically and experimentally. The problem is formulated in a form of a boundary integral equation and differential equations. The boundary integral equation is solved by the boundary element method and the finite difference method is used to solve the differential equations. An effect of a membrane wake is used in the analysis. The theoretical critical divergence velocity is compared with the experimental value.
\end{abstract}

\section{Introduction}

Stability of membranes in a flow has a practical meaning in the case of membrane roofs made of technical fabric used in civil engineering. At significant values of an air flow velocity divergence and flutter type of stability loss may occur. These problems were theoretically and experimentally analyzed by many authors (see, e.g. $[1,3,4,5]$ ).

In problems of structures in a fluid flow non-conservative loading takes place. Several papers were devoted to such an analysis. The influence of damping is especially important in the behaviour of such systems (see $[7,8,9]$ ).

Experiments in a wind tunnel carried out by the author on membranes made of latex rubber showed, that after the divergent loss of stability large deflections occur in membranes and subsequent phenomena are non-linear. It was observed, that the divergent mode was not symmetric with respect to the centre line $(x=l / 2)$. These experiments were a motivation to create a theoretical model, which would allow to obtain the mode similar to the one observed in the experiment.

In the theoretical model a membrane supported at two edges lying in a twodimensional subsonic flow is analyzed. The membrane wake formed behind the trailing edge was taken into account. The problem was described by one boundary integral equation and three differential equations. The boundary element method and the finite difference method were used in the solution.

\section{Experimental investigations}

Experimental testing of a membrane with length $l=535 \mathrm{~mm}$ and width $b=75 \mathrm{~mm}$ was carried out. The membrane was made of two $0.8 \mathrm{~mm}$ thick layers of latex rubber. It was simply-supported on two edges. The initial tension was $T=288 \mathrm{~N} / \mathrm{m}$. Figure 1 presents the sketch of the model. The wind tunnel, where the membrane stability tests were carried out is a closed circuit tunnel with a $920 \times 640 \mathrm{~mm}$ closed test section. The membrane behaviour was monitored by a video camera. 

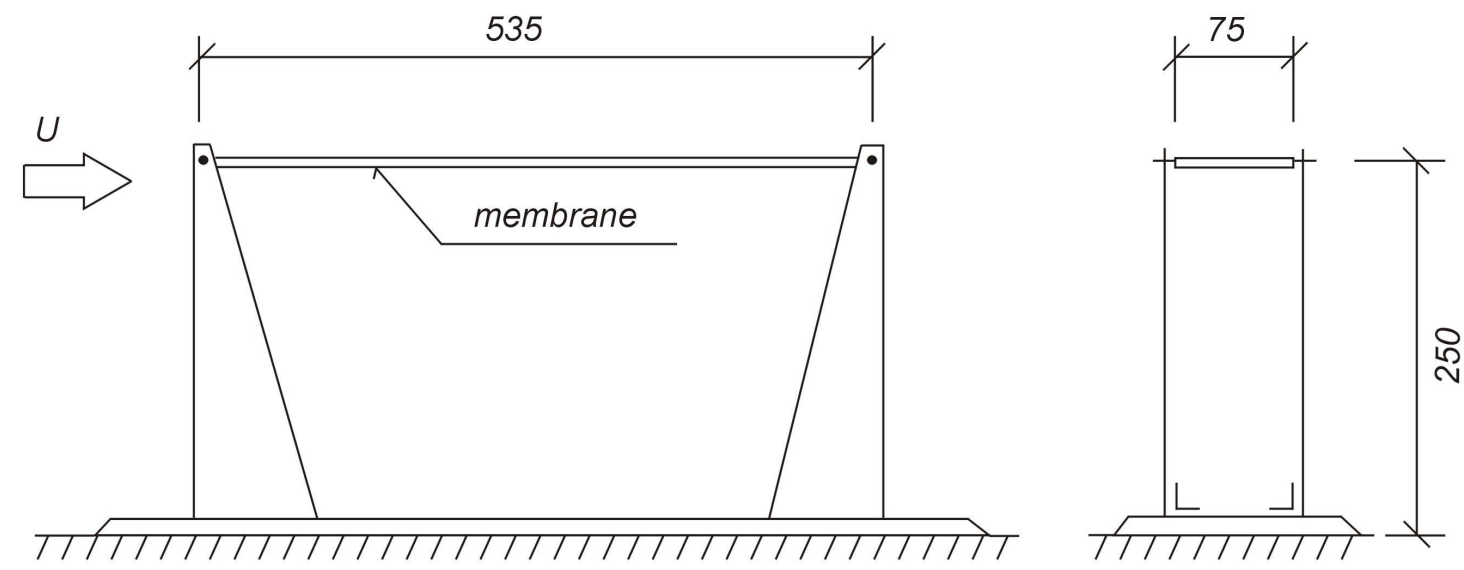

Fig. 1. View of membrane model

It was observed that a limited increase of the flow velocity resulted in a small increase in membrane deformation. Beyond $U=45 \mathrm{~m} / \mathrm{s}$ the deflection increased significantly and the membrane lost stability by divergence with a non-symmetric mode shape shown in Fig. 2(a). Further increase of the flow velocity led to larger membrane deflections and at about $U=58$ $\mathrm{m} / \mathrm{s}$ flutter-type oscillations around the already deflected membrane shape were observed. These vibrations formed a standing wave type of behaviour exhibiting a three half-waves mode shape as shown in Fig. 2(b.). The further increase of the flow velocity caused the increase of the flutter vibration amplitude. The relationship between the dimensional flow velocity versus the membrane deflection is shown in Fig. 3.

Additional testing on the stability of square, rectangular and circular membranes was carried out. Qualitatively, the same phenomena were observed in all these cases.
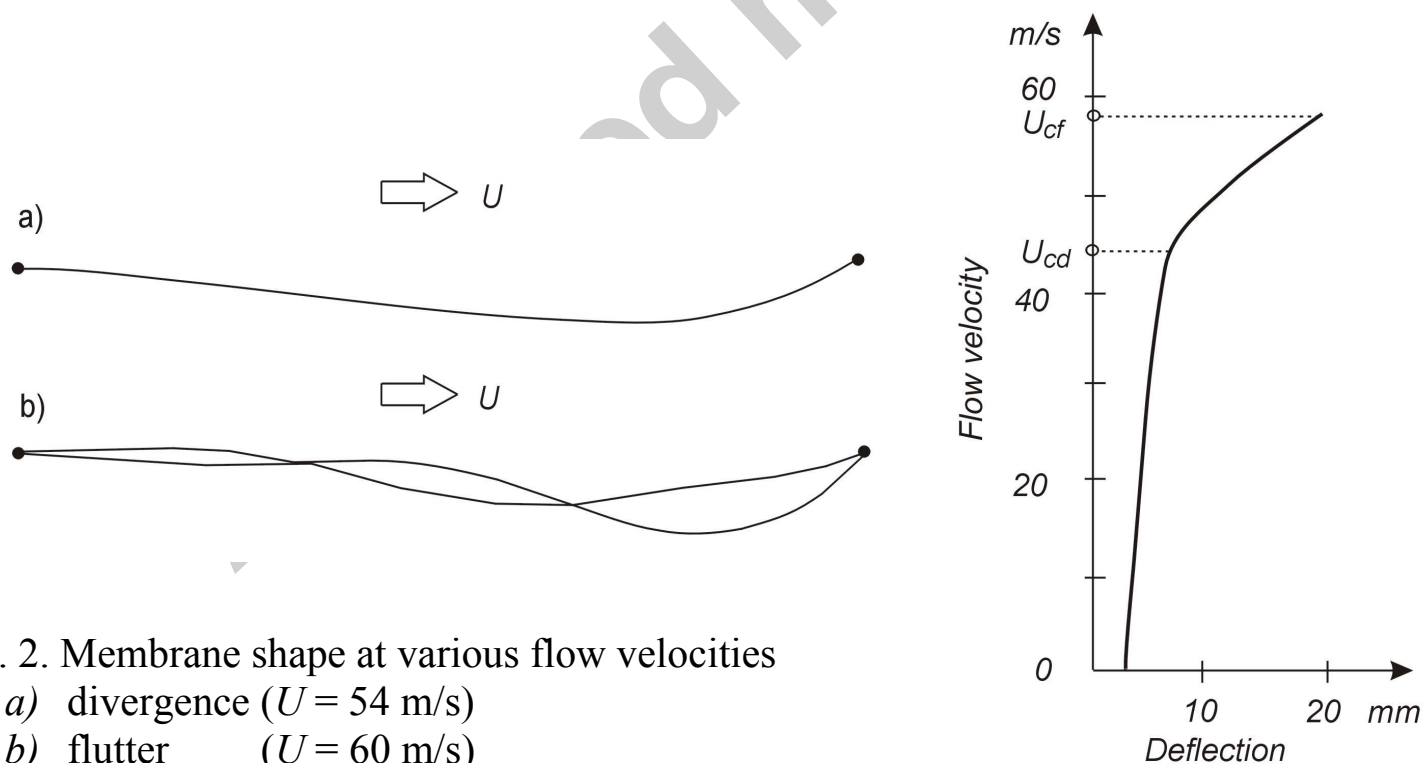
a) divergence $(U=54 \mathrm{~m} / \mathrm{s})$
b) flutter $(U=60 \mathrm{~m} / \mathrm{s})$

Fig. 2. Membrane shape at various flow velocities

Fig. 3. Flow velocity versus membrane deflection 


\section{Theoretical analysis}

The one-dimensional equation of motion of a membrane shown in Figure 4 subjected to a fluid flow on both sides is given by

$$
-T \frac{\partial^{2} w}{\partial x^{2}}+\mu \frac{\partial^{2} w}{\partial t^{2}}+\Delta p=0
$$

where $T$ is the tension in the membrane per unit length, $\mu$ - the membrane mass per unit area, $w \equiv w(x, t)$ - its lateral deflection, $\Delta p \equiv \Delta p(x, t)$ - the load per unit area on the membrane equal to the difference between the perturbation pressures on the upper and lower surfaces of the membrane caused by its deflection $\left(\Delta p=p_{1}-p_{2},\left|p_{1}\right|=\left|p_{2}\right|\right)$. The leading and trailing edges of the membrane are simply - supported.

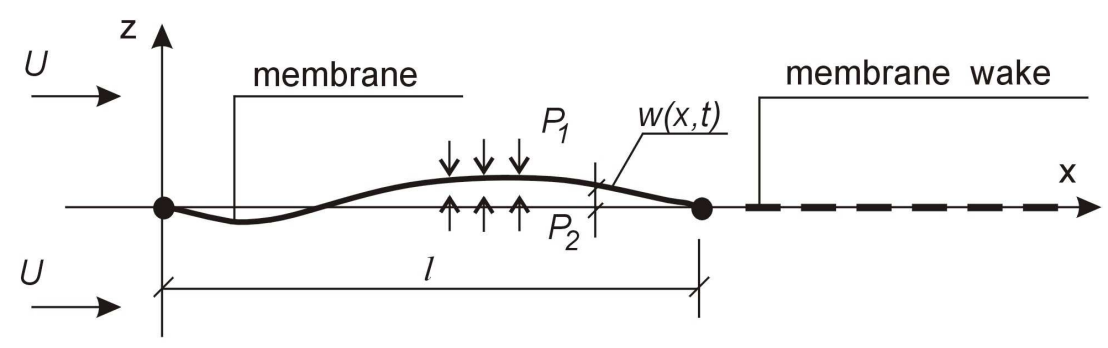

Fig. 4. Membrane in two-dimensional flow

Assuming an inviscid, incompressible two-dimensional flow, the perturbation pressures can be given by the unsteady Bernoulli equation

$$
\Delta p=-2 \rho\left[\frac{\partial \Phi}{\partial t}+U \frac{\partial \Phi}{\partial x}\right]_{z=0}
$$

where $\rho$ is the fluid density and $U$ - the unperturbed flow velocity. The perturbation velocity potential $\Phi \equiv \Phi(x, y, t)$ must satisfy the Laplace equation

$$
\frac{\partial^{2} \Phi}{\partial x^{2}}+\frac{\partial^{2} \Phi}{\partial z^{2}}=0
$$

The solution of equation (3) for an open surface (with the Neumann-type boundary condition on the surface) can be expressed by the following boundary integral equation

$$
\Phi(x, z, t)=-\frac{1}{2 \pi} \int_{S} \Delta \Phi\left(x^{\prime}, t\right) \frac{\partial}{\partial z}\left(\ln \left(1 / r^{\prime}\right)\right) d x^{\prime},
$$

where $r^{\prime 2}=\left(x-x^{\prime}\right)^{2}+z^{2}, \Delta \Phi\left(x^{\prime}, t\right)$ is the difference between the perturbation velocity potential on the upper and lower surfaces of the membrane $\left(\Delta \Phi=\Phi_{1}-\Phi_{2},\left|\Phi_{1}\right|=\left|\Phi_{2}\right|\right.$, 
$\left.\Delta \Phi=2 \Phi_{1}=2 \Phi\right)$ ). Differentiation of equation (4) with respect to $z$ and letting $z \rightarrow 0$ gives the normal component of the perturbation fluid velocity $v_{z}(x, t)$ on the membrane surface

$$
\left.\frac{\partial \Phi(x, z, t)}{\partial z}\right|_{z=0}=-\frac{1}{2 \pi} \int_{S} \Delta \Phi\left(x^{\prime}, t\right) \frac{\partial^{2}}{\partial z^{2}}\left(\ln \left(1 / r^{\prime}\right)\right) d x^{\prime},
$$

where $\partial \Phi(x, z, t) /\left.\partial z\right|_{z=0}=v_{z}(x, t)$.

The boundary condition on the membrane is of Neumann type and it is a coupling condition between the membrane and the fluid. It reads

$$
\left.\frac{\partial \Phi(x, z, t)}{\partial z}\right|_{z=0}=\frac{\partial w(x, t)}{\partial t}+U \frac{\partial w(x, t)}{\partial x} .
$$

Behind the trailing edge a membrane wake is formed. The trailing edge is still so the velocities of liquid particles across the wake are zero. Hence, the wake condition reads:

$$
v_{z}(x, t)=0 \text {. }
$$

\section{Numerical solution of the problem}

The problem was described by one boundary integral equation (5), three differential equations (1), (2) and (6) as well as by the wake condition (7). Upon separation of the space and time variables and expressing the solution with respect to time in the exponential form (e.g., $\Delta p(x, t)=\Delta \widetilde{p}(x) e^{\lambda t}, \lambda$ is the eigenvalue parameter, $\lambda=i \omega, i=\sqrt{-1}, \omega$ is the complex eigenfrequency $\left.\left(\omega=\omega_{R}+i \omega_{I}\right)\right)$, equations (1), (2), (5) and (6) yield

$$
\begin{aligned}
& -T \frac{\partial^{2} \widetilde{w}(x)}{\partial x^{2}}+\lambda \mu \widetilde{w}(x)+\Delta \widetilde{p}(x)=0, \\
& \Delta \widetilde{p}(x)=-2 \rho\left[\lambda \widetilde{\Phi}(x)+U \frac{\partial \widetilde{\Phi}(x)}{\partial x}\right], \\
& \widetilde{v}_{z}(x)=-\frac{1}{\pi} \int_{S} \widetilde{\Phi}\left(x^{\prime}\right) \frac{\partial^{2}}{\partial z^{2}}\left(\ln \left(1 / r^{\prime}\right)\right) d x^{\prime}, \\
& \widetilde{v}_{z}(x)=\lambda \widetilde{w}(x)+U \frac{\partial \widetilde{w}(x)}{\partial x} .
\end{aligned}
$$

The finite difference method (FDM) is used to solve differential equations (8), (9) and (11). The solution of the boundary integral equation (10) is determined by means of the boundary element method (BEM). Using the FDM to solve equations (8), (9) and (10), one obtains the following set of algebraic equations

$$
\begin{aligned}
& -T \mathbf{B}_{2} \widetilde{\mathbf{w}}+\lambda^{2} \mu \widetilde{\mathbf{w}}+\Delta \widetilde{\mathbf{p}}=\mathbf{0}, \\
& \Delta \widetilde{\mathbf{p}}=-2 \rho\left(\lambda \widetilde{\mathbf{\Phi}}+U \mathbf{B}_{1} \widetilde{\boldsymbol{\Phi}}\right), \\
& \widetilde{\mathbf{v}}=\lambda \widetilde{\mathbf{w}}+U \mathbf{B}_{1} \widetilde{\mathbf{w}}
\end{aligned}
$$


where $\widetilde{\mathbf{w}}, \Delta \widetilde{\mathbf{p}}, \widetilde{\mathbf{v}}$ and $\widetilde{\boldsymbol{\Phi}}$ are the vectors containing unknowns in the nodes (collocation points). Matrices $\mathbf{B}_{1}$ and $\mathbf{B}_{2}$ have the form

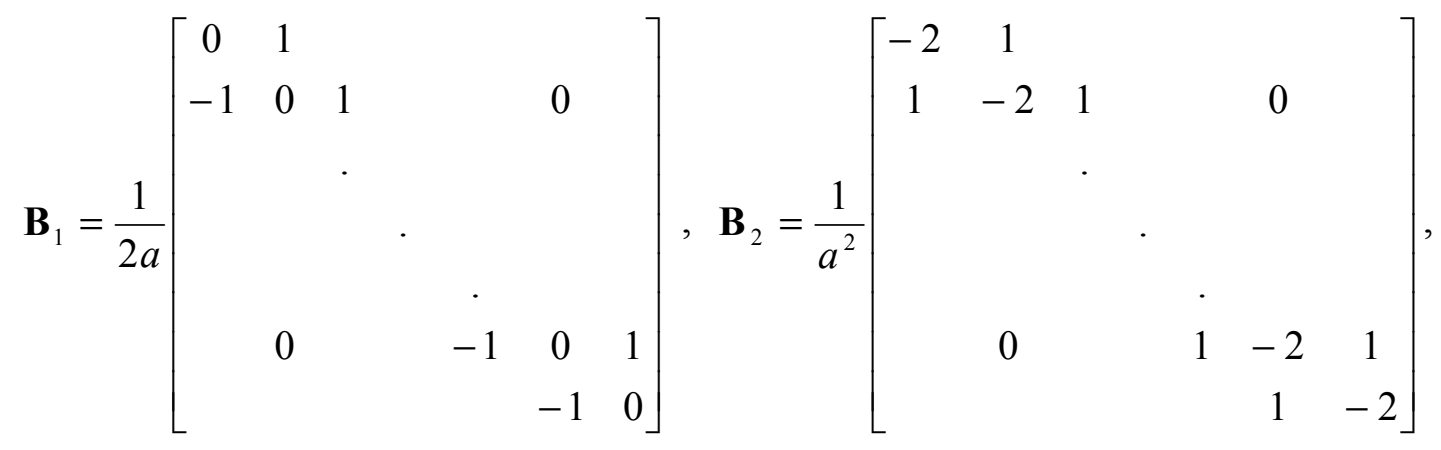

where $a$ is the distance between collocation points.

The boundary elements of constant type were used to discretize the boundary integral equation (10). The discretization yields the following matrix equation

$$
\widetilde{\mathbf{v}}=-\mathbf{A} \widetilde{\boldsymbol{\Phi}}
$$

After the differentiation and integration the entries of matrix $\mathbf{A}$ have the form

$$
A(i, j)=\frac{1}{\pi}\left(\frac{1}{r(i, j)+a / 2}-\frac{1}{r(i, j)-a / 2}\right),
$$

where $r(i, j)$ is the distance between collocation points $i$ and $j$.

In order to fulfil condition (7) collocation points located in the membrane wake (Fig. 5) were used. The matrix $\mathbf{A}$ in equation (16) is a rectangular matrix with dimensions $n_{1} \times n$, where $n_{1}=n+m, n$ is the number of the collocation points in the membrane and $m$ is the number of collocation points in the wake.

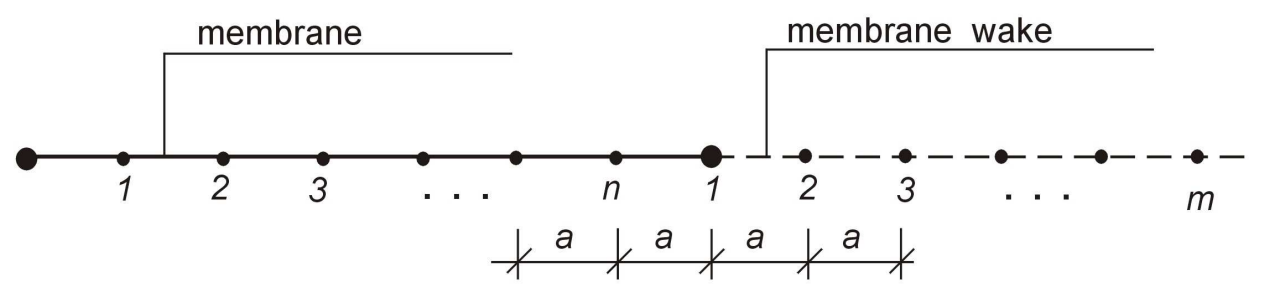

Fig. 5. Distribution of collocation points on membrane and its wake

From the equation (16) we get

$$
\widetilde{\boldsymbol{\Phi}}=-\mathbf{A}_{1}^{+} \widetilde{\mathbf{v}},
$$

where $\mathbf{A}_{1}^{+}$is a square matrix $n \times n$ extracted from the matrix $\mathbf{A}^{+}\left(\mathbf{A}_{\left(n \times n_{1}\right)}^{+}=\left[\mathbf{A}_{1(n \times n)}^{+} \mathbf{A}_{2(n \times m)}^{+}\right]\right)$.

Matrix $\mathbf{A}^{+}$is a pseudoinverse of matrix $\mathbf{A}$ and is calculated using singular value decomposition [6] 


$$
\mathbf{A}=\mathbf{U} \boldsymbol{\Sigma} \mathbf{V}^{T},
$$

where $\mathbf{U}$ and $\mathbf{V}$ are orthogonal matrices, $\boldsymbol{\Sigma}=\operatorname{diag}\left(\sigma_{i}\right), \sigma_{i}$ is the $i$-th singular value. Hence

$$
\mathbf{A}^{+}=\mathbf{V} \boldsymbol{\Sigma}^{+} \mathbf{U}^{T}
$$

where $\Sigma^{+}=\operatorname{diag}\left(\sigma_{i}^{+}\right), \sigma_{i}^{+}=1 / \sigma_{i}$.

From equations (18), (13) and (14) we get:

$$
\Delta \widetilde{\mathbf{p}}=2 \rho\left(\lambda^{2} \mathbf{A}_{1}^{+} \widetilde{\mathbf{w}}+\lambda U\left(\mathbf{A}_{1}^{+} \mathbf{B}_{1}+\mathbf{B}_{1} \mathbf{A}_{1}^{+}\right) \widetilde{\mathbf{w}}+U^{2} \mathbf{B}_{1} \mathbf{A}_{1}^{+} \mathbf{B}_{1} \widetilde{\mathbf{w}}\right) .
$$

Now substituting equation (21) into the membrane equation (12) yields the homogenous matrix equation

$$
\left(\mathbf{K}+\lambda \mathbf{G}+\lambda^{2} \mathbf{M}\right) \widetilde{\mathbf{w}}=\mathbf{0},
$$

where $\mathbf{K}=\mathbf{K}_{s}+\mathbf{K}_{a}, \mathbf{M}=\mathbf{M}_{s}+\mathbf{M}_{a}, \mathbf{K}_{s}=-T \mathbf{B}_{2}$ is the stiffness matrix of the membrane, $\mathbf{M}_{s}=\mu \mathbf{I}$ is the mass matrix of the membrane, $\mathbf{I}$ is the identity matrix, $\mathbf{M}_{a}=2 \rho \mathbf{A}_{1}^{+}$is the fluid mass matrix, $\mathbf{K}_{a}=2 \rho U^{2} \mathbf{B}_{1} \mathbf{A}_{1}^{+} \mathbf{B}_{1}$ is the fluid stiffness matrix and $\mathbf{G}=2 \rho U\left(\mathbf{A}_{1}^{+} \mathbf{B}_{1}+\mathbf{B}_{1} \mathbf{A}_{1}^{+}\right)$is the fluid matrix containing gyroscopic and damping forces. Equation (22) represents a quadratic eigenvalue problem. By introducing the new variable $\mathbf{w}^{*}=\lambda \widetilde{\mathbf{w}}$ it can be transformed to a standard eigenvalue problem

$$
\left[\begin{array}{cc}
\mathbf{0} & \mathbf{I} \\
-\mathbf{M}^{-1} \mathbf{K} & -\mathbf{M}^{-1} \mathbf{G}
\end{array}\right]\left\{\begin{array}{c}
\widetilde{\mathbf{w}} \\
\mathbf{w}^{*}
\end{array}\right\}-\lambda\left\{\begin{array}{c}
\widetilde{\mathbf{w}} \\
\mathbf{w}^{*}
\end{array}\right\}=\left\{\begin{array}{l}
\mathbf{0} \\
\mathbf{0}
\end{array}\right\} .
$$

The eigenvalues of equation (23) for an assumed flow velocity $U$ allow one to determine the character of the membrane motion and to predict, whether the membrane motion is stable or unstable. For the case when $\lambda=0$ (static loss of stability) equation (22) is reduced to

$$
\left(\mathbf{K}_{s}-U^{2} \mathbf{K}_{1}\right) \widetilde{\mathbf{w}}=\mathbf{0},
$$

where $\mathbf{K}_{1}=-2 \rho \mathbf{B}_{1} \mathbf{A}_{1}^{+} \mathbf{B}_{1}$. Equation (24) is a generalized eigenvalue problem. By solving this problem one obtains the critical velocities of the divergent type instability of the membrane.

\section{Numerical results}

Computer programs were written based on the formulation presented in Sections 3 and 4. The dimensionless parameters used in the analysis are $\overline{U^{2}}=U^{2} \rho l / T, \overline{\omega^{2}}=\omega^{2} l^{2} \mu / T$ and $\bar{\mu}=\mu /(\rho l)$, where $\bar{U}$ is the dimensionless flow velocity, $\bar{\omega}$ is the dimensionless frequency and $\bar{\mu}$ is the dimensionless mass of the membrane. 
The divergence velocity of the membrane was calculated using equation (24). Fifty collocation points on the membrane and on its wake were used. The calculations were performed with and without the wake. The theoretical model predicted loss of stability by divergence at $\bar{U}_{c d}=1.76$ when the wake effect was included in the model and loss of stability at $\bar{U}_{c d}=1.67$ when the wake effect was eliminated from the model. The divergent modes for both cases are presented in Fig. 6. It is clear that the inclusion of the wake in the calculations yields a non-symmetric mode shape solution. This results coincides with the observation from experiments in a wind tunnel (see Fig. 2a). For the membrane used in the experiment the theoretical value of divergence velocity $U_{c d}=37 \mathrm{~m} / \mathrm{s}$ and the experimental value $U_{c d}=45 \mathrm{~m} / \mathrm{s}$. The difference is about $18 \%$.

a)
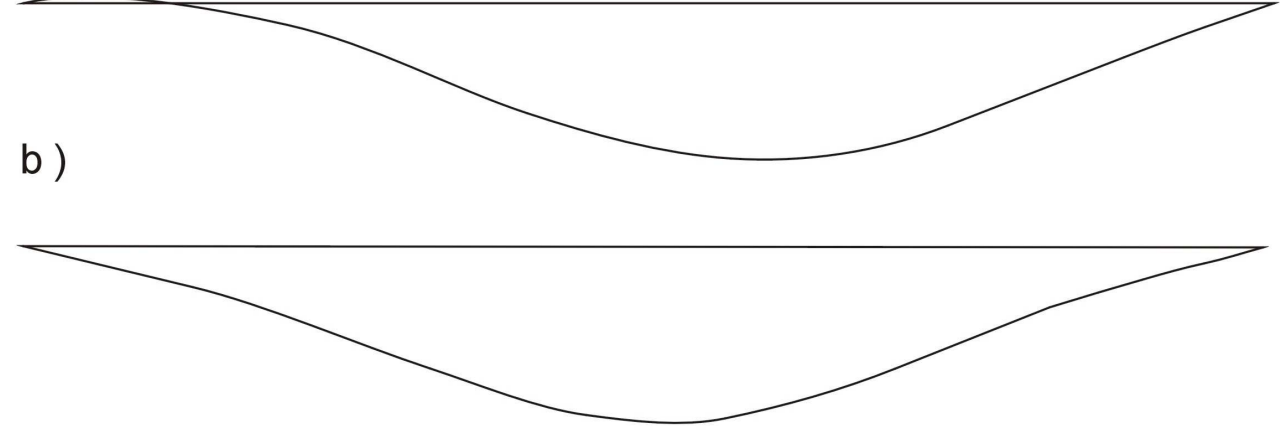

Fig. 6. Divergence mode, $a$ ) with wake, $b$ ) without wake

The relationship of $\overline{U^{2}}$ versus real and imaginary parts of the eigenfrequencies $\overline{\omega_{R}}$ and $\overline{\omega_{I}}$ relationship for $\bar{\mu}=1.0$ and $\bar{\mu}=0.1$ for the cases with and without wake are given in Figs. 7 and 8, respectively. It can be observed that including the effect of the membrane wake influences significantly the theoretical results. For the membrane with the wake nonzero imaginary parts of the eigenfrequency are observed prior to divergence (see Figs. 7(b) and $8(\mathrm{~b})$ ). At $\bar{U}_{c d}=1.76$ the membrane loses stability by divergence and at higher flow velocity $\bar{U}_{f l}=2.00$ for $\bar{\mu}=1.0$ and $\bar{U}_{f l}=2.22$ for $\bar{\mu}=0.1$, the system loses stability by single mode flutter. For the case in which the wake effects are not considered, the imaginary part of the eigenfrequency is zero prior to divergence (see Figs. 7(a) and 8(a)). In this case the membrane loses stability by divergence at $\bar{U}_{c d}=1.67$. At higher flow velocity, $\bar{U}_{f l}=2.03$ for $\bar{\mu}=1.0$ and $\bar{U}_{f l}=2.15$ for $\bar{\mu}=0.1$, the membrane loses stability by classical coupled-mode flatter.

Similar phenomena were reported in [2] for a plate with symmetric boundary conditions (e.g. pinned-pinned case) and with non-symmetric boundary conditions (e.g. clamped-pinned case).

The inclusion of the membrane wake in the theory caused non-symmetric flow conditions on the leading and trailing edges. 
a)

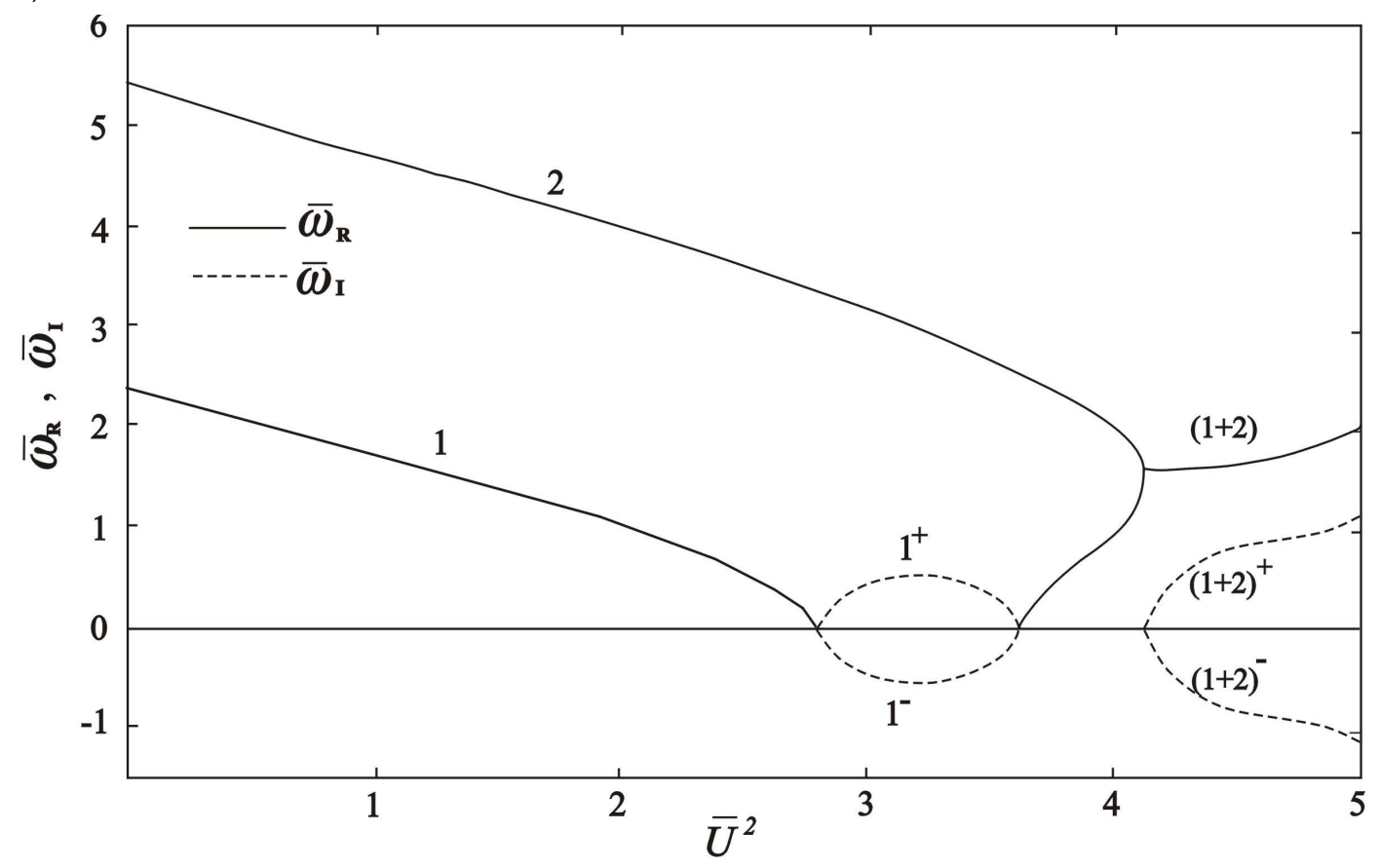

b)

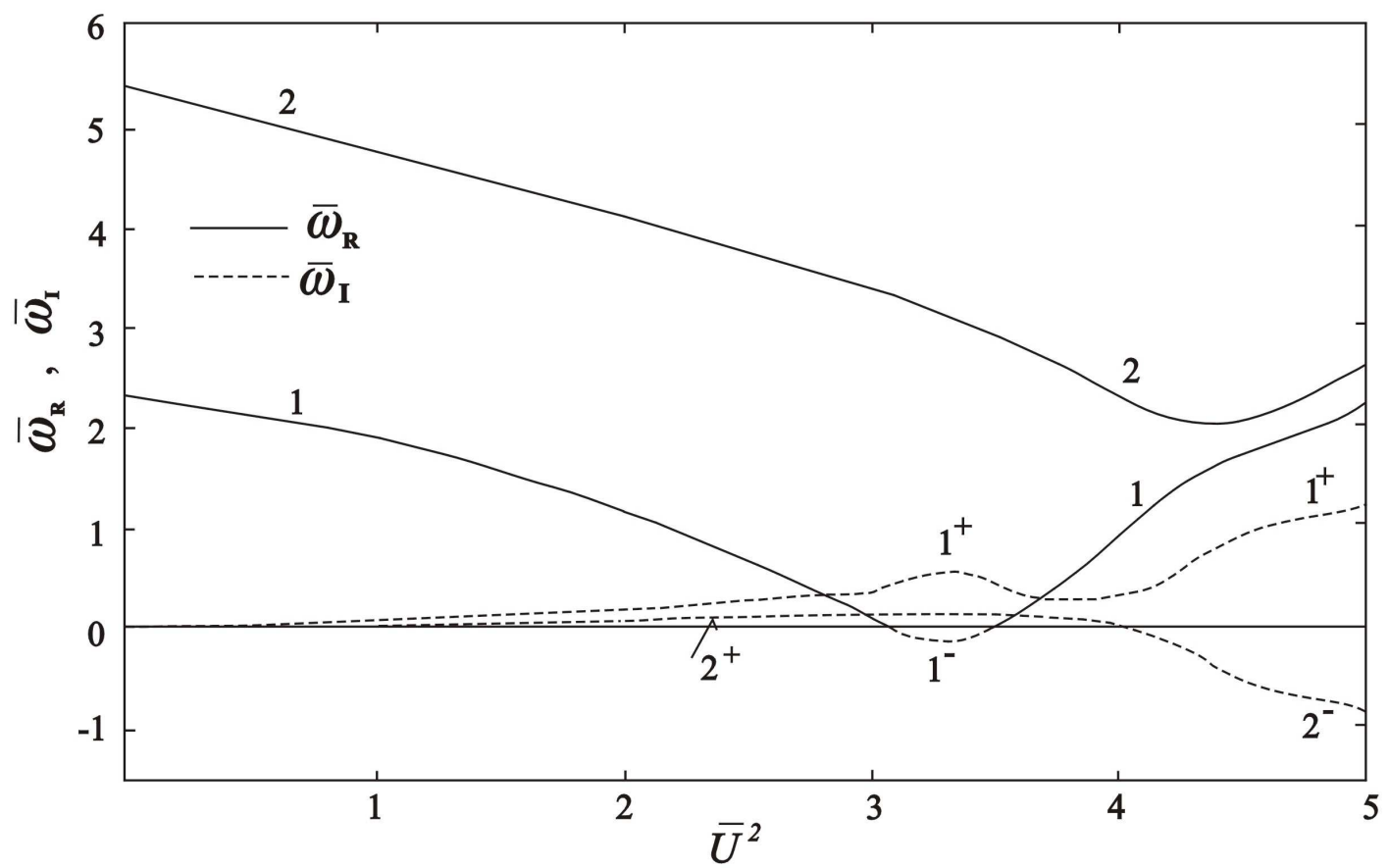

Fig. 7. Dimensionless complex eigenfrequencies versus squared dimensionless velocity, $\bar{\mu}=1.0, a$ ) without wake, $b$ ) with wake 

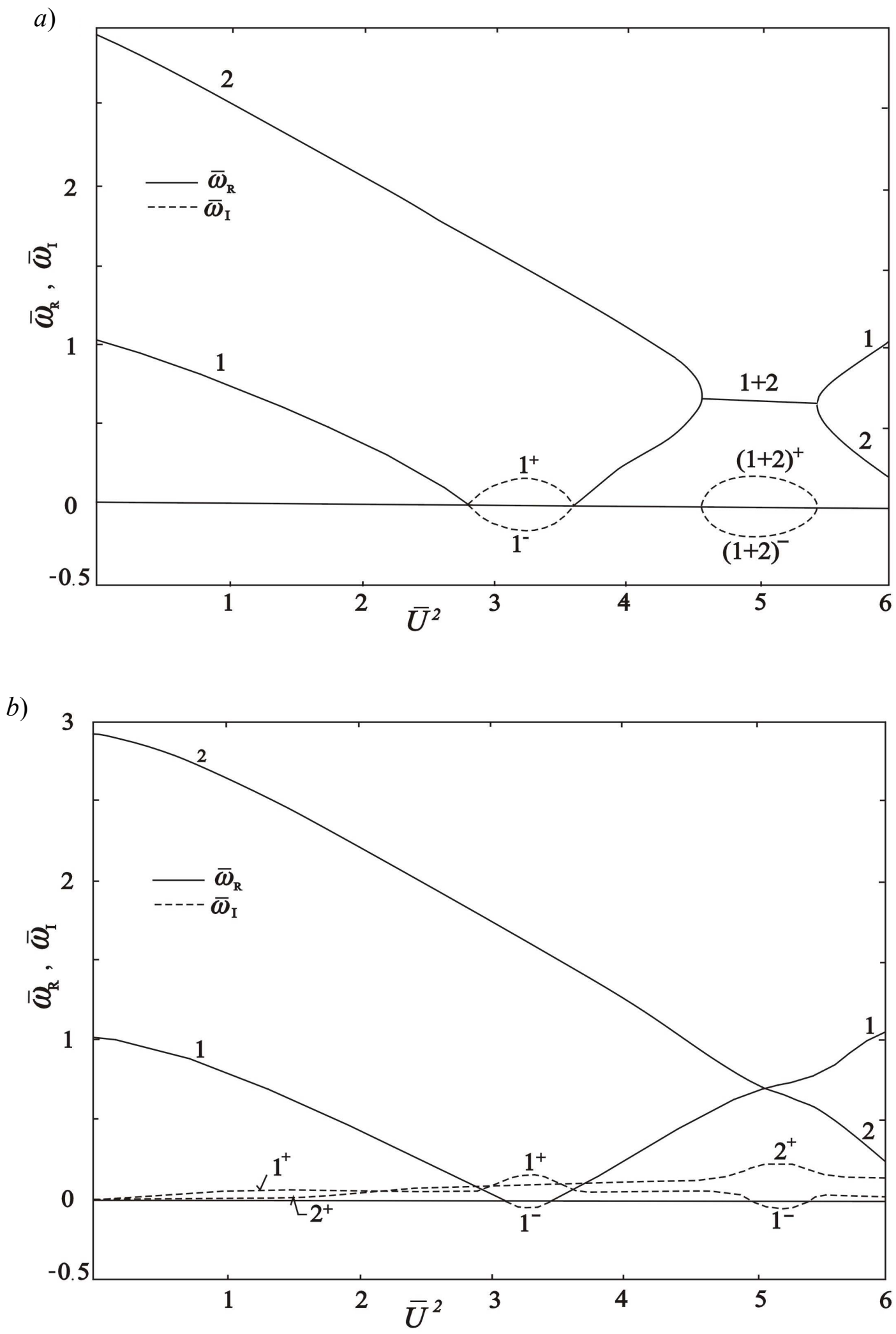

Fig. 8. Dimensionless complex eigenfrequencies versus squared dimensionless velocity, $\bar{\mu}=0.1, a$ ) without wake, $b$ ) with wake 


\section{Conclusions}

Results of theoretical and experimental analysis of stability of a membrane in a twodimensional subsonic flow are presented in this paper. The influence of membrane wake on its stability was investigated. The problem related to membranes has not been analysed yet. The boundary element method and the finite difference method were used in the numerical solution of the problem.

The following conclusions can be stated:

1. Divergent mode of stability loss for a membrane is not symmetric.

2. Experiments show, that flutter vibrations occur around the divergent deflected shape of the membrane and have a form of a standing wave.

3. Inclusion of the membrane wake in the theoretical model allowed to get a nonsymmetric divergent mode, similar to the experimental one.

4. The linear model of the membrane stability is valid until the divergent loss of stability. The increase of the flow velocity beyond this limit leads to a significant membrane deflection and the calculation of the subsequent flutter velocity would require a nonlinear model.

\section{References}

1. C. H. Ellen, The stability of an Isolated Rectangular Surface Embedded in Uniform Subsonic Flow, ASME J. Appl. Mech., June 1977, pp. 201-206.

2. C. Q. Guo, M. P. Paidoussis, Stability of rectangular plates with free side-edges in two-dimensional inviscid channel flow, ASME J. Appl. Mech., Vol. 67, March 2000, pp. 171-176.

3. B. G. Newman, M. P. Paidoussis, The stability of two-dimensional membranes in streaming flow, J. of Fluids and Structures, 1991, 5, pp. 443-454.

4. R. Sygulski, Numerical analysis of membrane stability in air flow, J. of Sound and Vibration, 1997, 201 (3), pp. 281-292.

5. M. P. Paidoussis, Fluid-structure interaction, slender structures and axial flow, vol. 2, Elsevier Academic Press, 2004

6. G. E. Forsythe, M. A. Malcolm and C. B. Moler, Computer Methods for Mathematical Computations, Prentice-Hall, Englewood Cliffs, NJ, 1977.

7. A. N. Kounadis, Hamiltionian Weakly Damped Autonomous System Exhibiting Periodic Attractors, ZAMP, 2006, 57, pp. 324-350.

8. V. V. Bolotin, A. A. Grishko, M. Y. Panov, Effect of damping on the postcritical behaviour of autonomous non-conservative systems, Int. J. Non-Linear Mechanics, 2002, 37 (7) pp. 1163-1179.

9. V. V. Bolotin, A. A. Grishko, A. N. Kounadis, C. J. Gantes, Non-linear panel flutter in remote post-critical domains, Int. J. Non-Linear Mechanics, 1998, 33 (5) pp. 753-764. 